\title{
Application of an Automated Headspace Solid Phase Micro-Extraction for the GC-MS Detection and Quantification of Reductive Sulfur Compounds in Wines
}

\author{
Dang-Dung Nguyen, Laura Nicolau and Paul A. Kilmartin \\ School of Chemical Sciences, \\ The University of Auckland, \\ New Zealand
}

\section{Introduction}

Aromatic substances are among the key determinants of food and beverage quality, owing to their interactions with the senses of smell and taste. These can then determine consumer acceptance or rejection of a product. The aroma of foods is influenced by different compounds, among which sulfur containing compounds are an important group due to their abundance and aromatic impact. Likewise, wine contains various sulfur containing structures which have a major sensorial impact and play a significant role in wine aroma and flavour. Among these, certain sulfur containing volatiles can contribute to favourable sensory impacts, while others can have detrimental effects on wine quality. The latter refers to the off-odours that have been a major concern for the wine industry.

The analysis of reductive sulfur compounds in wine is a challenging task. This is due to three main problems, namely the complexity of the wine matrix, the low concentrations of the reductive sulfur compounds, and their highly reactive nature. In order to obtain good sensitivity, specificity and reliability, reductive sulfur compounds are usually analysed by gas chromatography coupled either with sulfur-specific detectors such as the flame photometric detector, the pulsed flame photometric detector, the sulfur chemiluminescent detector, or with a non-sulfur specific detector such as a mass spectrometry detector or an atomic emission detector. This chapter reports on an automated Headspace Solid Phase Micro-Extraction procedure followed by Gas Chromatography-Mass Spectrometry used for the detection and quantification of the common highly volatile (light) and less volatile (heavy) sulfur compounds in wine. These are defined as having boiling points below and above $90{ }^{\circ} \mathrm{C}$, respectively, which is the boiling point of 3-(methylthio)-1-propanol. The methodology is based upon a publication by Fedrizzi et al. (2007), with additional considerations given to the choice of the SPME fiber for optimum extraction efficiency, the addition of magnesium sulfate to increase extraction yield, and other parameters such as extraction time and the choice of temperature to improve the Solid Phase Micro-Extraction methodology (Pawliszyn, 1997). 
Table 1 below presents some information about the perception thresholds, odour descriptions and the concentrations of the reductive sulfur compounds commonly reported in the wine literature (Spedding \& Raut, 1982; Mestres et al., 2002; Fang \& Qian, 2005; Ribéreau-Gayon et al., 2006b; Landaud et al., 2008). Fourteen reductive sulfur compounds, out of sixteen compounds presented in this table, are the analytes of interest in the current study.

\begin{tabular}{|c|c|c|c|}
\hline Sulfur compounds & $\begin{array}{c}\text { Perception } \\
\text { threshold } \\
\text { in wines } \\
(\mu \mathrm{g} / \mathrm{L})\end{array}$ & Odour description & $\begin{array}{l}\text { Concentration } \\
\text { range in } \\
\text { wines } \\
(\mu \mathrm{g} / \mathrm{L})\end{array}$ \\
\hline \multicolumn{4}{|l|}{ Highly volatile } \\
\hline Hydrogen sulfide & $0.001-150$ & Rotten eggs & nd - 370 \\
\hline Methanethiol & $0.3^{* *}$ & Cooked cabbage & nd - 16 \\
\hline Ethanethiol & 1.1 & Onion, rubber, putrefaction & nd - 50 \\
\hline Dimethyl sulfide & $10-160$ & $\begin{array}{l}\text { Cabbage, asparagus, corn, } \\
\text { molasses }\end{array}$ & nd - 910 \\
\hline Carbon disulfide & $>38$ & Cabbage, rubber & nd -18 \\
\hline Dimethyl trisulfide & $0.1^{*}$ & $\begin{array}{l}\text { Cabbage, onion, cooked } \\
\text { vegetables }\end{array}$ & nd - 111 \\
\hline \multicolumn{4}{|l|}{ Less volatile } \\
\hline Diethyl sulfide & $0.93-18$ & Garlic & nd -10 \\
\hline Dimethyl disulfide & $20-45$ & Cooked cabbage, asparagus, onion & $0-22$ \\
\hline Diethyl disulfide & $4.3-40$ & Garlic, onion, burnt rubber & nd - 85 \\
\hline 2-Mercaptoethanol & 130 & Barnyard-like (böxer), poultry & nd - 400 \\
\hline Methylthioacetate & $300^{*}$ & Sulfury, rotten vegetables & nd - 115 \\
\hline S-Ethylthioacetate & $40^{*}$ & Sulfury & nd - 180 \\
\hline $\begin{array}{l}\text { 2-(Methylthio)-1- } \\
\text { ethanol }\end{array}$ & $250^{* *}$ & Cauliflower, French bean & $88-139$ \\
\hline $\begin{array}{l}\text { 3-(Methylthio)-1- } \\
\text { propanol }\end{array}$ & 1200 & Cooked cabbage, cauliflower & $145-5655$ \\
\hline $\begin{array}{l}\text { 4-(Methylthio)-1- } \\
\text { butanol }\end{array}$ & 100 & Earthy, chive-garlic, onion & nd - 181 \\
\hline Benzothiazole & $50-350$ & Rubber & $0-30$ \\
\hline
\end{tabular}

Table 1. Common reductive sulfur compounds in wines

\section{Material and methods}

\subsection{Chemicals and reagents}

Fourteen reductive sulfur compounds of interest, ranging from highly volatile compounds such as thiols and disulfides to less volatile compounds, S-thioesters and thioether alcohols, were included. Of note is that another highly volatile compound, methanethiol, was also successfully detected and quantified without the use of a cryotrap, together with further high and low volatile sulfur compounds, commonly reported in the wine literature.

The fourteen reductive sulfur compounds were methanethiol (MeSH) (CAS No. 74-93-1), ethanethiol (EtSH) (75-08-1), dimethyl sulfide (DMS) (75-18-3), diethyl sulfide (DES) (352-93- 
2), S-methyl thioacetate (MTA) (1534-08-3), S-ethyl thioacetate (ETA) (625-60-5), dimethyl disulfide (DMDS) (624-92-0), diethyl disulfide (DEDS) (110-81-6), carbon disulfide (CS2) (7515-0), dimethyl trisulfide (DMTS) (3658-80-8), 2-mercaptoethanol (ME) (60-24-2), 2(methylthio)-1-ethanol (MTE) (5271-38-5), 3-(methythio)-1-propanol (MTP) (505-10-2) and 4(methylthio)-1-butanol (MTB) (20582-89-3). ${ }^{2} \mathrm{H}_{6}$-Dimethyl sulfide (926-09-0), isopropyl disulfide (4523-89-8) and 3-(methylthio)-1-hexanol (51755-66-9) were used as internal standards. The commercial standards were purchased from either Sigma-Aldrich (Auckland, New Zealand) or Alfa Aesa (Ward Hill, MA, USA). A methanethiol gas cylinder was supplied by Matheson Coleman and Bell (East Rutherford, NJ, USA). The standards were used to identify peaks in the chromatograms and to construct calibration curves for quantification purposes.

\subsection{Sample extraction conditions}

A pre-concentration step is required before chromatographic analysis of reductive sulfur compounds, due to their trace concentrations in wine. Solid Phase Micro-Extraction, a technique introduced in 1980s, has been increasingly used as an alternative to traditional pre-concentration methods, for the extraction of volatile compounds. It is a 'solvent-less' technique that employs a polymer-coated fiber immersed into a liquid sample or the gas headspace to extract and concentrate analytes from the matrix onto the fiber. The method allows the use of smaller sample volumes. Through the use of an automated Headspace Solid Phase Micro-Extraction (HS-SPME) procedure to extract the sulfur analytes onto the fiber, high through-put of samples is possible with minimal variations during sample preparation. The Gas Chromatography - Mass Spectrometry (GC-MS) method development for the analysis of reductive sulfur containing compounds was based on a publication of Fedrizzi et al. (2007).

\subsubsection{Selection of fiber coating}

Different fibers are commercially available for use with SPME. Volatile analytes are retained more effectively on a thicker fiber coating and can be transferred into the GC injection port without losses. On the other hand, a thin coating is used to ensure rapid release of higher boiling point compounds during thermal desorption (Otles, 2009).

The commercially available SPME fibers can generally be classified into two groups. The first group involves a pure liquid polymer coating, such as polydimethylsiloxane (PDMS) and polyacrylate. The second group are mixed films containing solid particles and liquid polymers, such as Carboxen-polydimethylsiloxane (CAR-PDMS) and divinylbenzenepolydimethylsiloxane (DVB-PDMS) (Otles, 2009). Carboxen acts as a carbon molecular sieve ${ }^{1}$ and is often used with PDMS for low molecular weight polar analytes, while DVB-PDMS is more suited to semi-polar analytes (Otles, 2009).

In the method reported by Fedrizzi et al. (2007), fibers with six different coatings were examined for their extraction efficiency with regard to reductive sulfur containing compounds. Although other 'light' sulfur compounds were included in the current study, the Divinylbenzene/Carboxen-Polydimethylsiloxane (DVB/CAR-PDMS; 50/30 $\mu \mathrm{m} \times 2 \mathrm{~cm}$ ) fiber (Product No. 57298U, Supelco, Bellefonte, PA, USA) provided the best results, and was

1 To trap very small molecular sized compounds (C2-C5) 
employed to extract the analytes of interest. The fiber is a mixed film coated with Divinylbenzene/Carboxen on polydimethylsiloxane, bonded to a flexible fused silica that offers a less breakable fiber. The mixed film coating allows the extraction of the analytes by absorption with the liquid polymer and by adsorption with the porous solid particles.

\subsubsection{Extraction and agitation}

Incubation of the samples prior to extraction was carried out in order to give similar conditions before the fiber was exposed to the headspace for the extraction of the analytes.

Agitation using magnetic stirrer bars was employed during both incubation and extraction steps using a Gerstel Agitator/Stirrer, in which the agitation speed and temperature were automatically controlled using MAESTRO Software (Version 1.2.0) (Gerstel, Mülheim an der Ruhr, Germany). Variations in agitation conditions during incubation and extraction were therefore eliminated.

The extraction temperature and time were optimised, as part of the current method development, to give the best extraction effectiveness for the reductive sulfur compounds of interest. The experimental protocols and results are presented in Section 3.1.

\subsection{Chromatographic conditions}

Analysis of the reductive sulfur compounds was carried out on an Agilent Technologies 7890 GC system coupled with a 5975C inert XL MSD (Agilent Technologies, Santa Clara, CA, USA). Separation was performed on a tandem column composed of a $30 \mathrm{~m} \times 0.320 \mathrm{~mm}$ x $0.25 \mu \mathrm{m} \mathrm{HP}-1 \mathrm{MS}^{2}$ and a $30 \mathrm{~m} \times 0.320 \mathrm{~mm} \times 0.25 \mu \mathrm{m}$ HP-Innowax ${ }^{3}$ fused silica capillary column (Agilent, J\&W Scientific, New Zealand). The transfer line temperature was set at 250 ${ }^{\circ} \mathrm{C}$. Helium was used as the carrier gas at an initial flow rate of $1.8 \mathrm{~mL} / \mathrm{min}$, held for $5 \mathrm{~min}$, then lowered to $1.5 \mathrm{~mL} / \mathrm{min}$ for the rest of the run.

Different conditions, including injection temperatures and oven temperature programs, have been trialled to obtain good peak separation. The final conditions involved an injection port temperature of $250{ }^{\circ} \mathrm{C}$. The oven temperature was initially set at $42{ }^{\circ} \mathrm{C}$ for $5 \mathrm{~min}$, then ramped at $1.5^{\circ} \mathrm{C} / \mathrm{min}$ to $60^{\circ} \mathrm{C}$ and at $4{ }^{\circ} \mathrm{C} / \mathrm{min}$ to $150{ }^{\circ} \mathrm{C}$, held for $5 \mathrm{~min}$. After that, it was ramped at $40{ }^{\circ} \mathrm{C} / \mathrm{min}$ to $230{ }^{\circ} \mathrm{C}$ and remained at this temperature for $10 \mathrm{~min}$, until a final ramp at $70{ }^{\circ} \mathrm{C} / \mathrm{min}$ back to $42^{\circ} \mathrm{C}$ towards the end of the run.

\subsection{Peak identification}

The ions used for the identification and quantification of each compound were chosen according to the literature and NIST library. The resulting retention times of the analysed compounds and of the internal standards are presented in Table 2.

Fig.1 displays the peak separations of the internal standards and the investigated reductive sulfur compounds, obtained from an injection of a standard solution into the GC-MS system, as described in Section 2.3.

${ }^{2}$ Non-polar column with stationary phase made of $100 \%$ dimethylpolysiloxane

${ }^{3}$ Highly polar column with stationary phase made of polyethylene glycol 

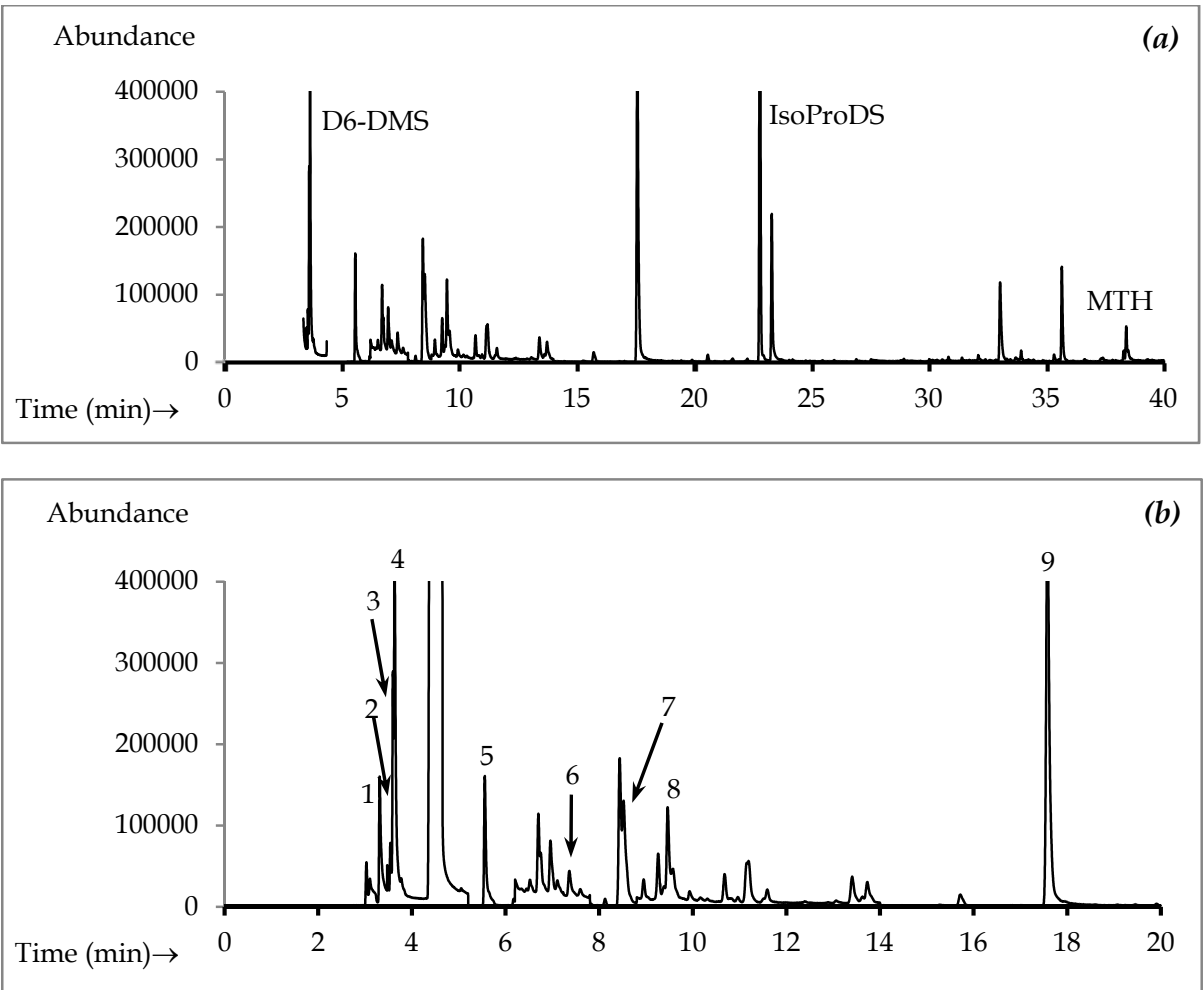

Abundance

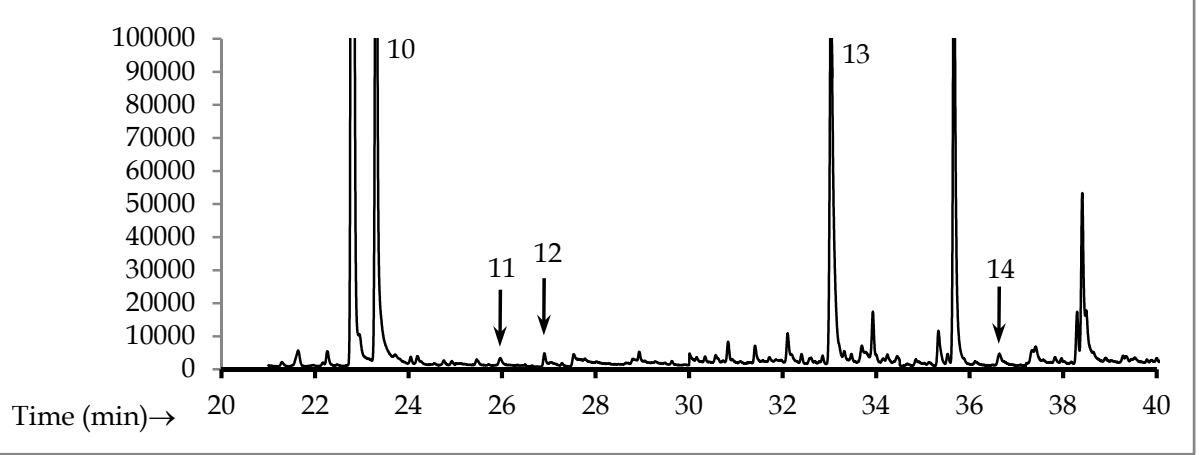

Fig. 1. Total ion chromatograms of a standard solution showing peaks for the internal standards (a): D6-DMS, m/ z 68; IsoProDS, m/z 150; MTH m/z 148; and of the analytes (b \& c): 1- MeSH, m/ z 47; 2- EtSH, m/z 62; 3- DMS, m/ z 62; 4- CS2, m/ z 78; 5- DES, m/ z 75; 6- MTA, m/z 90; 7- DMDS, $\mathrm{m} / \mathrm{z}$ 79; 8- ETA, m/ z 104; 9- DEDS, $\mathrm{m} / \mathrm{z}$ 122; 10- DMTS, $\mathrm{m} / \mathrm{z}$ 126; 11- ME, m/ z 47; 12-MTE, m/z 92; 13- MTP, m/ z 106; 14- MTB, $\mathrm{m} / \mathrm{z} 120$. The chromatographic conditions are described in Section 2.3 and the abbreviations used for the compounds can be seen in Table 2. 


\begin{tabular}{|c|c|c|c|}
\hline Chemicals and reagents & Abbreviations & $\begin{array}{c}\text { Quantifier ion } \\
\text { (Qualifier ions) }\end{array}$ & $\begin{array}{l}\text { Retention time } \\
\text { (min) }\end{array}$ \\
\hline \multicolumn{4}{|l|}{ Analytes } \\
\hline Methanethiol & $\mathrm{MeSH}$ & $47(45,48)$ & 3.3 \\
\hline Ethanethiol & $\mathrm{EtSH}$ & $62(34,47)$ & 3.53 \\
\hline Dimethyl sulfide & DMS & $62(47,61)$ & 3.61 \\
\hline Carbon disulfide & CS2 & $78(44,76)$ & 3.62 \\
\hline Diethyl sulfide & DES & $75(61,62,90)$ & 5.54 \\
\hline Methyl thioacetate & MTA & $90(43,47,75)$ & 7.22 \\
\hline Dimethyl disulfide & DMDS & $79(61,64,94)$ & 8.51 \\
\hline S-Ethyl thioacetate & ETA & $104(43,60,62)$ & 9.45 \\
\hline Diethyl disulfide & DEDS & $122(66,94)$ & 17.56 \\
\hline Dimethyl trisulfide & DMTS & $126(64,79)$ & 23.29 \\
\hline 2-Mercaptoethanol & $\mathrm{ME}$ & $47(60,78)$ & 25.96 \\
\hline 2-(Methylthio)-1-ethanol & MTE & $92(47,61)$ & 26.82 \\
\hline 3-(Methylthio)-1-propanol & MTP & $106(57,58,61)$ & 33.02 \\
\hline 4-(Methylthio)-1-butanol & МТВ & $120(61,87,102)$ & 36.62 \\
\hline \multicolumn{4}{|l|}{ Internal standards } \\
\hline${ }^{2} \mathrm{H}_{6}$-Dimethyl sulfide & D6-DMS & $68(66,50)$ & 3.58 \\
\hline Isopropyl disulfide & IsoProDS & $150(108,66)$ & 22.78 \\
\hline 3-(Methylthio)-1-hexanol & MTH & $148(61,75)$ & 38.41 \\
\hline
\end{tabular}

Table 2. Retention times and ions used for the identification and quantification of the reductive sulfur compounds

\subsection{Calibration}

\subsubsection{Preparation of deodourised wine for calibration}

A simple method was employed to prepare a base wine for constructing a calibration curve for the quantification of the reductive sulfur compounds. Deodourisation of the base wine was carried out in order to remove the volatile sulfur compounds as much as possible, along with other volatile compounds, while retaining further components of the wine to obtain a matrix effect similar to that of a wine sample.

A research red wine (Cabernet Sauvignon) was used to construct the calibration curves for the reductive sulfur compounds of interest. The wine was deodourised twice using a Büchi Rotavapor R (BÜCHI Labortechnik AG, Flawil, Switzerland) sourced from Watson Victor Ltd., Australia \& New Zealand. An aliquot of the wine $(200 \mathrm{~mL})$ was put in an evaporation flask placed in a water bath and the temperature was maintained at $30{ }^{\circ} \mathrm{C}$. After the first evaporation, the wine was reconstituted with absolute ethanol and ultrapure water (Barnstead ${ }^{\circledR}$ NANOpure DIamond ${ }^{\mathrm{TM}}$ Water Purification System) and was evaporated for a second time. The wine was then reconstituted with absolute ethanol and ultrapure water to have $13.5 \% \mathrm{v} / \mathrm{v}$ ethanol in the final reconstituted wine.

\subsubsection{Preparation of a global stock mixture of reductive sulfur compounds}

Stock solutions of all thirteen reductive sulfur compounds, as mentioned in Section 2.1, except methanethiol, were separately prepared by introducing $50 \mu \mathrm{L}$ of a commercial 
standard by a SGE $100 \mu \mathrm{L}$ gas tight syringe (Part No. 005250 100R-GT, Phenomenex NZ Ltd., New Zealand) into an amber screw top $20 \mathrm{~mL}$ vial (Part No. 5188-6537) (Agilent Technologies) containing $10 \mu \mathrm{L}$ absolute ethanol and pre-flushed with an inert gas, closed with a certified ultraclean $18 \mathrm{~mm}$ screwcap with septum (Part No. 5188-2759, Agilent Technologies). Weight differences together with purities were then used to calculate the final concentrations. These stock solutions were stored at $-80^{\circ} \mathrm{C}$.

Methanethiol was prepared by bubbling methanethiol gas through $10 \mathrm{~mL}$ ethanol in a collecting vial, which was placed in a dry ice container. The methanethiol stock solution was stored at $-20^{\circ} \mathrm{C}$. All stock solutions had concentrations in the range between 1 and $15 \mathrm{~g} / \mathrm{L}$.

In order to construct the calibration curves, a global stock mixture in absolute ethanol of all the reductive sulfur compounds of interest was prepared from the individual sulfur stock solutions already made up from commercial standards. The volume of the individual stock solutions needed was calculated so that the final concentrations of reductive sulfur compounds in the standard solutions fell in the concentration ranges for wines reported in the literature.

The global stock mixture of reductive sulfur compounds was prepared using a SGE gas tight syringe, by adding the required amounts of individual stock sulfur compounds into a $20 \mathrm{~mL}$ amber vial containing the required volume of absolute ethanol. The vial had been previously purged with argon gas and closed with a certified ultraclean $18 \mathrm{~mm}$ screwcap with septum.

\subsubsection{Preparation of the internal standard mixture}

Individual stock solutions of internal standards were prepared in similar way as the reductive sulfur stock solutions. A mixture of internal standards was then prepared from the individual solutions, with the concentration of ${ }^{2} \mathrm{H}_{6}$-dimethyl sulfide at $5 \mathrm{mg} / \mathrm{L}$, isopropyl disulfide at $0.4 \mathrm{mg} / \mathrm{L}$ and 3-(methylthio)-1-hexanol at $10 \mathrm{mg} / \mathrm{L}$. Their addition led to concentrations in the wine samples of $25 \mu \mathrm{g} / \mathrm{L}, 2 \mu \mathrm{g} / \mathrm{L}$ and $50 \mu \mathrm{g} / \mathrm{L}$, respectively. The internal standard mixture was stored at $-20{ }^{\circ} \mathrm{C}$ for daily usage.

${ }^{2} \mathrm{H}_{6}$-Dimethyl sulfide was used to quantify methanethiol, ethanethiol, dimethyl sulfide, diethyl sulfide, methyl thioacetate, S-ethyl thioacetate. Isopropyl disulfide was used for dimethyl disulfide, diethyldisulfide, carbon disulfide, dimethyl trisulfide. Other compounds including 2-mercaptoethanol, 2-(methylthio)-1-ethanol, 3-(methythio)-1-propanol and 4-(methylthio)-1butanol were quantified using 3-(methylthio)-1-hexanol as the internal standard.

\subsubsection{Preparation of standard solutions for calibration}

Standard solutions used to build the calibration curves were prepared by adding the required volume of the global stock mixture into a $20 \mathrm{~mL}$ amber vial containing the reconstituted deodourised red wine (Section 2.5.1).

The vial had been purged with argon gas and closed with a certified ultraclean $18 \mathrm{~mm}$ screwcap with septum before introducing the global stock mixture of sulfur compounds through a SGE gas tight syringe to have a total sample volume of $10 \mathrm{~mL}$. An aliquot of $50 \mu \mathrm{L}$ internal standard solution (Section 2.5.3) was then placed in the vial before HS-SPME extraction and GC-MS analysis. 


\subsection{Method validation}

A two-step approach was used for the determination of method detection and quantification limits for the sulfur analytes, as described in Lee \& Aizawa (2003). The two step approach takes into consideration several factors that affect the analyte signal, including instrumental noise, variability in instrumental sensitivity, and variability in method efficiency, matrix effects and interference, and is simple to follow. Other methods, such as the Hubaux-Vos approach for the calculation of the detection limit can also be used, as reported in Fedrizzi et al. (2007). However, this later approach is complicated, time consuming and does not take either the variability in method efficiency or the matrix effects into consideration (Lee \& Aizawa, 2003). A brief discussion on how to conduct the method validation using the two steps approach is mentioned in this section.

Each analytical instrument has a limitation in the amount of an analyte that can be detected. In addition, with complex matrices, interfering components cannot be completely eliminated, so their effects must be taken into account when determining the limit of detection (LOD) for an analyte-matrix combination. The LOD, for most modern analytical methods, can therefore be divided into two components, instrumental detection limit (IDL) ${ }^{4}$ and method detection limit (MDL) 5 . A similar notion can be used for the limit of quantification (LOQ).

The approach described in Lee \& Aizawa (2003) consists of two steps for the determination of the LOD and LOQ. These firstly involve determination of the Instrumental Detection Limit (IDL) and Instrumental Quantification Limit (IQL), and using these values to estimate the Method Detection Limit (MDL) and Method Quantification Limit (MQL), following calculation of the LOD and LOQ for the extraction/analysis method.

Step 1. Determination of IDL and IQL following the Root Mean Square Error method

The Root Mean Square Error (RMSE) method, recommended by the US Environmental Protection Agency, involves generation of a calibration curve and calculating the RMSE. The steps involved are as follows:

1. Generate a 4-5 point calibration curve with standards having concentrations within an order of magnitude 6 of the estimated detection limit. The detection limit may be estimated as a concentration that would produce a signal three times the peak-to-peak noise. The calibration curve should be generated by plotting the detector's response against concentration.

2. Perform a regression analysis on the calibration curve and calculate values for the slope (m) and intercept (i) for a number of standards (n).

3. The calibration curve generated by plotting detector response $(\mathrm{x})$ versus concentration (c) is:

$$
\mathrm{x}=\mathrm{m} \cdot \mathrm{c}+\mathrm{i}
$$

\footnotetext{
${ }^{4}$ IDL is the smallest amount of an analyte that can be reliably detected or differentiated from the background of an instrument.

${ }^{5} \mathrm{MDL}$ is the smallest amount of an analyte that can be reliably detected or differentiated from the background for a particular matrix by a specific method. It should be applied to extraction and analysis methods developed for the analysis of specific analytes in a matrix.

${ }^{6}$ The concentrations of these standards are within a factor of 10 of the estimated detection limits.
} 
4. Based on the values of slope $(\mathrm{m})$ and intercept (i), calculate the predicted response $\left(\mathrm{x}_{\mathrm{P}}\right)$ for each of the standards.

5. Calculate the error (E) associated with each measurement $\left|\mathrm{x}_{\mathrm{P}-\mathrm{x}}\right|$.

6. Calculate the square of the errors for each standard and then calculate the sum of the square of the errors $\left(\sum E^{2}\right)$ associated for the number of points (n).

7. After that, the RMSE is calculated as follows:

$$
\text { RMSE }=\left[\sum E^{2} / n-2\right]^{1 / 2}
$$

8. The predicted instrumental detection limit (IDL, $\left.\mathrm{C}_{\mathrm{L}}\right)$ is calculated as follows:

$$
\mathrm{c}_{\mathrm{L}}=3 \cdot \mathrm{RMSE} / \mathrm{m}
$$

9. The predicted instrumental quantification limit $\left(\mathrm{IQL}, \mathrm{c}_{\mathrm{Q}}\right)$ is calculated using:

$$
\mathrm{CQ}_{\mathrm{Q}}=10 . \mathrm{RMSE} / \mathrm{m}
$$

The detection and quantification limits determined here $\left(\mathrm{c}_{\mathrm{L}}\right.$ and $\left.\mathrm{c}_{\mathrm{Q}}\right)$ do not take the matrix interferences into account, because RMSE was determined from calibration standards. The value $c_{Q}$ is used in the next step to spike the blank to compute the LOD and LOQ of the method, which incorporates instrumental variations. Consequently, both matrix/analytes and the extraction/analysis are taken into account for the determination of LOD and LOQ.

Step 2. The t99 $\sigma_{\text {LLMV }}$ method to calculate the values of LOD and LOQ

1. Fortify the 'blank' with the analytes of interest (7 replicates) such that the concentration of the analytes in the matrix equals the estimated LOQ (eLOQ) as determined in the aforementioned step (the $\mathrm{c}_{\mathrm{Q}}$ value).

2. Extract and analyse these samples following the method used for sample analysis.

3. Determine the amount of each analyte in the fortified samples.

4. Calculate the standard deviation of these measurements $\left(\sigma_{\mathrm{eLOQ}}{ }^{7}\right)$.

5. Determine the 'one-tailed t-statistic' for $\mathrm{n}-1$ observations at the $99 \%$ confidence level $\left(t_{99(n-1)}\right)$. The $t_{99(n-1)}$ for 7 replicates (6 degrees of freedom) is 3.413.

6. The method detection limit or limit of detection (LOD) and method qualification limit or limit of quantification (LOQ) for the matrix/analytes combination and the extraction/analysis procedure is computed as:

$$
\begin{gathered}
\mathrm{LOD}=\mathrm{t}_{99(\mathrm{n}-1) \cdot \sigma_{\mathrm{ELOQ}}=3.413 \sigma_{\mathrm{eLOQ}}} \\
\mathrm{LOQ}=3 . \mathrm{LOD}
\end{gathered}
$$

\section{Results and discussion}

\subsection{Extraction time and extraction temperature}

At room temperature, the concentration of semi-volatiles in the gaseous phase is small. The mass transfer rates are thus substantially lower, resulting in a longer extraction time using a coated fiber compared to direct extraction (Pawliszyn, 1997). One of the options to shorten

\footnotetext{
${ }^{7}$ According to the definition the lowest level of method validation (LLMV), the standard deviation of the concentration of the analyte in these fortified samples ( $\left.\sigma_{\text {eLOQ }}\right)$ is the $\sigma_{\text {LLMV, }}$ which explains the name of the method (the t996LLMV method).
} 
the extraction time is to increase the extraction temperature. An increased extraction temperature leads to greater diffusion coefficients and decreased distribution constants. An elevated temperature, therefore, can effectively assist in the dissociation of analytes from the matrix and their movement into the headspace. This leads to a faster equilibration time for a more rapid extraction (Pawliszyn, 1997). Temperature, therefore, is a very important parameter to optimise.
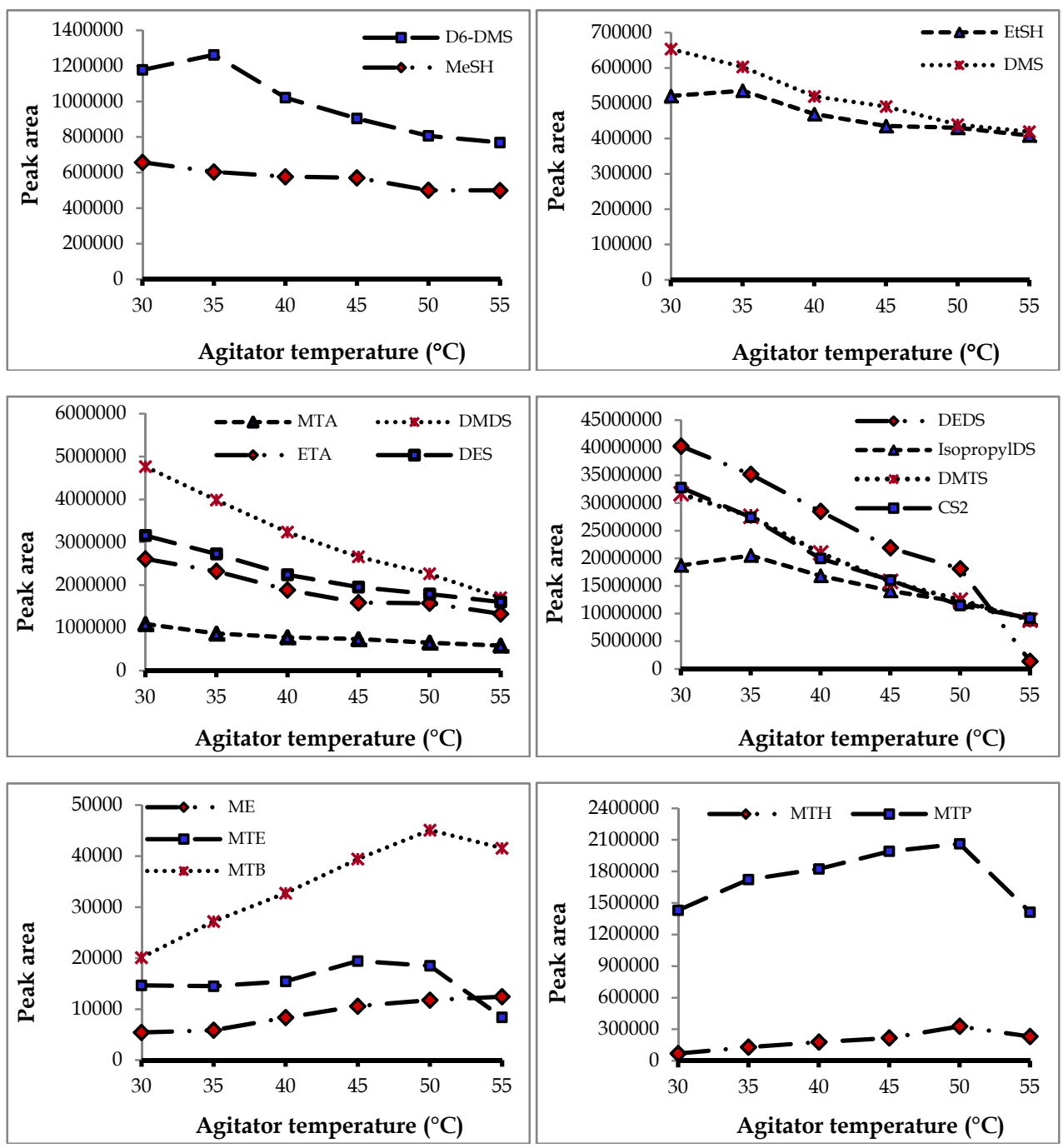

Fig. 2. Effect of extraction temperature on the chromatographic profile of the reductive sulfur compounds 
Fig. 2 presents the chromatographic profile, based on peak areas, of the reductive sulfur compounds, extracted at five different temperatures from $30^{\circ} \mathrm{C}$ to $55{ }^{\circ} \mathrm{C}$. As can be seen from these graphs, increasing the temperature led to a decrease in the amounts of the lighter sulfur compounds extracted onto the fiber. On the other hand, increasing the temperature to $50{ }^{\circ} \mathrm{C}$ resulted in increased peak areas for the heavier compounds, including ME, MTE, MTB, MTP and MTH. In order to get larger amounts of heavier compounds onto the fiber, without too much decrease in the quantity of the lighter reductive sulfur compounds, $45^{\circ} \mathrm{C}$ was chosen as a compromise temperature.
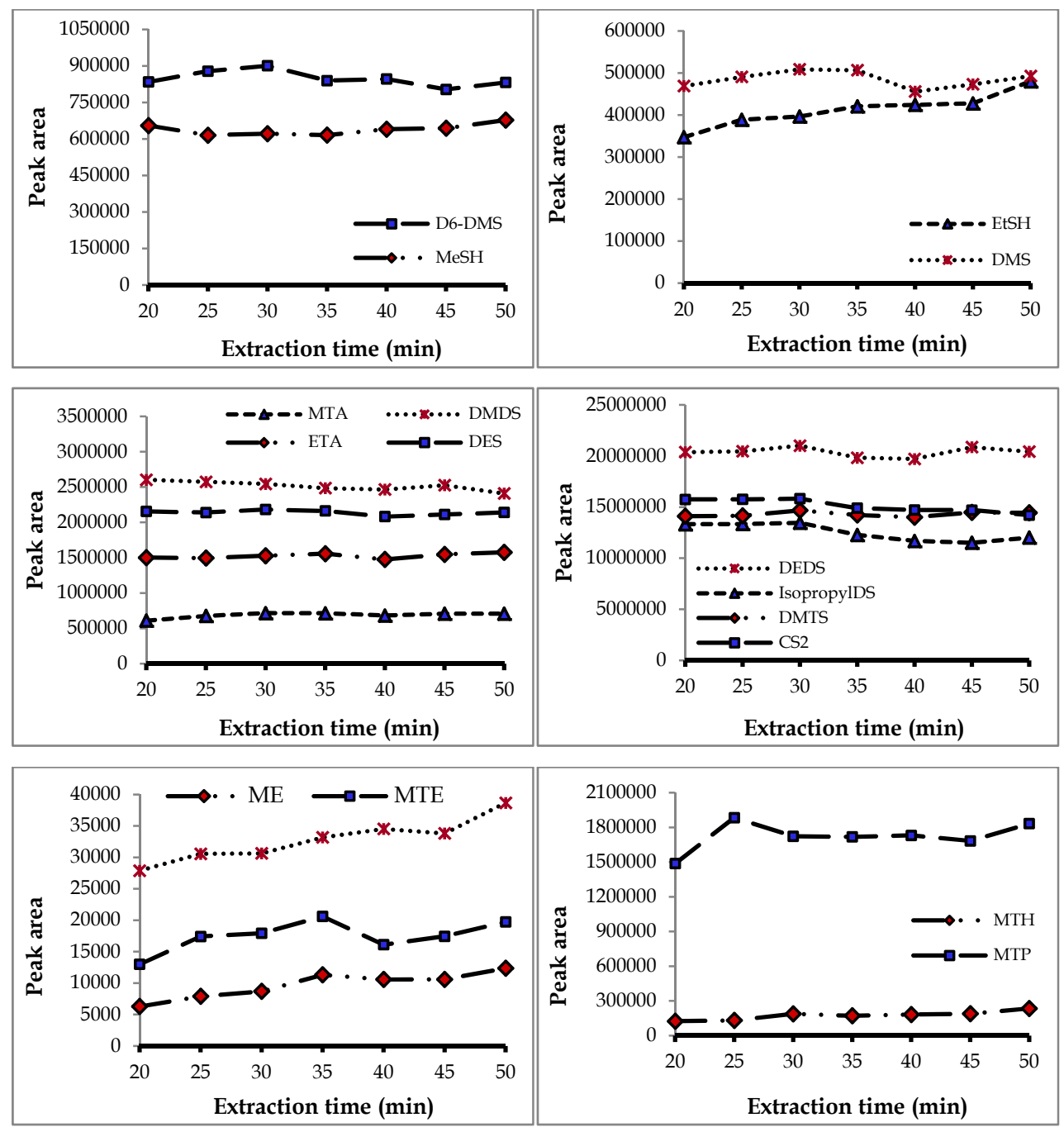

Fig. 3. Effect of extraction time on the chromatographic profile of the reductive sulfur compounds (continued) 
The optimisation of the extraction time was also based on similar theory to the effect of increasing extraction temperature. Similar results were found when samples were extracted for different periods of time, from 20 to $50 \mathrm{~min}$ (Fig.3). The effect of extraction time on the chromatographic profile of the sulfur compounds was much less than the effect of temperature. Prolonging the extraction time to $35 \mathrm{~min}$ gradually increased the peak areas of most compounds. Increasing the extraction time from 30 to $35 \mathrm{~min}$ did not increase the peak areas of the heavy sulfur compounds very much, but led to a decline in peak areas for some of the lighter compounds such as D6-DMS, CS2, and also DMDS and DEDS. Therefore, an extraction time of $30 \mathrm{~min}$ was selected, with a practical consideration being the desire to keep the extraction time reasonably short.

The optimised HS-SPME extraction conditions and other parameters finally selected for use in sample preparation prior to GC-MS analysis are given in Table 3.

\begin{tabular}{|l|l|}
\hline Parameters & Conditions \\
\hline Fiber coating & $\begin{array}{l}\text { CAR-PDMS-DVB; } \\
50 / 30 \mu \mathrm{m} \times 2 \mathrm{~cm} \\
\text { (Product No. 57928-U, Supelco) }\end{array}$ \\
\hline Sample volume & $10 \mathrm{~mL}$ \\
\hline Salt addition & $\begin{array}{l}1 \mathrm{M} \mathrm{MgSO} .7 \mathrm{H}_{2} \mathrm{O} \\
(2.5 \mathrm{~g} \mathrm{in} 10 \mathrm{~mL} \text { sample) }\end{array}$ \\
\hline Agitation speed & $\begin{array}{l}350 \mathrm{rpm} \\
(10 \mathrm{sec} \text { on, } 3 \mathrm{sec} \text { off })\end{array}$ \\
\hline $\begin{array}{l}\text { Incubation } \\
\text { Incubation time }\end{array}$ & $5 \mathrm{~min}$ \\
\hline $\begin{array}{l}\text { Extraction } \\
\text { Extraction time } \\
\text { Extraction temperature }\end{array}$ & $\begin{array}{l}{ }^{\circ} \mathrm{C} \\
45^{\circ} \mathrm{C}\end{array}$ \\
\hline
\end{tabular}

Table 3. Selected sample preparation conditions for HS-SPME extraction of the reductive sulfur compounds

\subsection{Calibration, detection and quantification limits}

Table 4 summarises the parameters obtained from the calibration graphs for all of the reductive sulfur analytes, along with the method detection and quantification limits for each compound. Linear regression analysis revealed that very good linearities $\left(R^{2}>0.992\right)$ were obtained in the calibration graphs for all of the reductive sulfur compounds. The method provided very good detection limits, which were well below the sensory thresholds (See Table 1) of the analysed sulfur compounds. 


\begin{tabular}{|l|c|c|c|c|c|c|c|}
\hline Compounds & $\begin{array}{c}\text { Concentration } \\
\text { range in the } \\
\text { calibration }(\mu \mathrm{g} / \mathrm{L})\end{array}$ & Slope & Intercept & $\mathbf{R}^{\mathbf{2}}$ & $\begin{array}{c}\text { eLOQ } \\
(\mu \mathrm{g} / \mathrm{L})\end{array}$ & $\begin{array}{c}\text { LOD } \\
(\mu \mathrm{g} / \mathrm{L})\end{array}$ & $\begin{array}{c}\text { LOQ } \\
(\mu \mathrm{g} / \mathrm{L})\end{array}$ \\
\hline MeSH & $0.40-16.1$ & 6.33 & -0.80 & 0.993 & 0.37 & 0.16 & 0.49 \\
\hline EtSH & $0.34-13.7$ & 11.87 & -1.02 & 0.994 & 0.28 & 0.12 & 0.36 \\
\hline DMS & $0.80-32.1$ & 26.09 & 0.23 & 0.993 & 0.14 & 0.14 & 0.42 \\
\hline CS2 & $0.44-17.7$ & 110.7 & 0.32 & 0.994 & 0.14 & 0.08 & 0.23 \\
\hline DES & $0.40-16.0$ & 4.12 & -0.14 & 0.995 & 0.25 & 0.03 & 0.10 \\
\hline MTA & $0.85-34.0$ & 32.94 & 0.08 & 0.998 & 0.39 & 0.15 & 0.44 \\
\hline DMDS & $0.24-9.4$ & 41.00 & 0.01 & 0.992 & 0.10 & 0.13 & 0.38 \\
\hline ETA & $0.86-34.5$ & 9.01 & 0.27 & 0.996 & 0.31 & 0.03 & 0.09 \\
\hline DEDS & $0.39-15.5$ & 4.61 & 0.21 & 0.996 & 0.12 & 0.06 & 0.19 \\
\hline DMTS & $0.45-17.9$ & 8.69 & 0.83 & 0.995 & 0.40 & 0.07 & 0.20 \\
\hline ME & $11.9-237.1$ & 2075 & 4.01 & 0.994 & 7.0 & 8.5 & 25.6 \\
\hline MTE & $3.79-75.7$ & 315.3 & 1.15 & 0.994 & 1.20 & 4.4 & 13.1 \\
\hline MTP & $78.3-3130.1$ & 172.4 & -10.98 & 0.996 & 29.5 & 8.4 & 25.2 \\
\hline MTB & $3.41-136.6$ & 280.9 & 0.79 & 0.995 & 2.71 & 7.8 & 23.3 \\
\hline
\end{tabular}

Table 4. Parameters from the calibration graphs, along with method detection and quantification limits

\subsection{Recovery and repeatability}

Two red wines (Mission Estate 2009 Cabernet Merlot, Corbans 2009 Merlot) and a white wine (Oyster Bay 2008 Sauvignon blanc), after being deodorised and reconstituted with absolute ethanol and ultrapure water (See Section 2.5.1), were spiked with known amounts of the sulfur compounds. The non-spiked and the spiked reconstituted wines were then analysed in triplicate using the SPME extraction conditions given in Table 2 and the GC-MS separation and analysis conditions provided in Section 2.3. The concentrations were calculated by interpolation using the corresponding calibration curves. The recovery (R) $(\%)$ was estimated as:

$$
\mathrm{R}=\left[\left(\mathrm{C}_{\mathrm{s}}-\mathrm{C}_{0}\right) * 100\right] / \mathrm{C}_{\mathrm{a}}
$$

where

$C_{s} \quad$ - Calculated concentration in the spiked wine

$C_{0} \quad$ - Calculated concentration in the non-spiked wine

$C_{a} \quad$ - Concentration added

The repeatability of the method was also evaluated by calculating the relative standard deviation (\% RSD) $(n=3)$ for each compound using equation (8).

$$
\% \operatorname{RSD}=\left(\mathrm{STD}^{*} 100\right) / \text { Mean }
$$

where

$\% R S D$ - Relative standard deviation (\%) of the mean 
STD - Standard deviation of the mean

Mean - Mean value

Table 5 presents the calculated recoveries and the \% RSD figures, which showed the good precision of the method for all of the analysed sulfur compounds. The recovery values were close to $100 \%$ and the \% RSDs were less than $10 \%$ for all of the compounds.

\begin{tabular}{|l|c|c|c|}
\hline Compounds & Red wine 1 & Red wine 2 & White wine \\
\hline MeSH & $108.6(5.0)$ & $107.7(2.6)$ & $101.3(0.7)$ \\
\hline EtSH & $94.7(3.1)$ & $96.6(6.8)$ & $104.8(2.8)$ \\
\hline DMS & $97.2(1.3)$ & $95.5(2.9)$ & $90.9(4.8)$ \\
\hline CS2 & $98.9(4.0)$ & $104.8(5.1)$ & $105.9(3.4)$ \\
\hline DES & $109.1(3.5)$ & $106.1(0.39)$ & $99.8(2.1)$ \\
\hline MTA & $109.5(4.8)$ & $110.0(2.5)$ & $94.0(0.10)$ \\
\hline DMDS & $96.3(6.8)$ & $97.4(7.5)$ & $94.6(10.1)$ \\
\hline ETA & $99.6(2.7)$ & $109.7(4.4)$ & $91.7(6.1)$ \\
\hline DEDS & $100.3(5.0)$ & $105.9(5.3)$ & $92.3(7.1)$ \\
\hline DMTS & $105.5(4.0)$ & $94.5(1.8)$ & $90.4(7.5)$ \\
\hline ME & $92.1(8.8)$ & $100.3(13.8)$ & $106.3(0.10)$ \\
\hline MTE & $94.9(4.4)$ & $85.9(6.2)$ & $96.5(1.3)$ \\
\hline MTP & $88.5(6.7)$ & $106.8(6.0)$ & $98.8(1.9)$ \\
\hline MTB & $84.9(4.3)$ & $94.4(9.3)$ & $95.7(0.85)$ \\
\hline
\end{tabular}

Table 5. Recovery values (\%), and in brackets the repeatability (RSD, in \%)

\section{Application}

The method reported in this chapter was then employed to investigate the reductive sulfur compounds in some New Zealand red and white wines. It was particularly applied for the quantification of reductive sulfur compounds during red wine micro-oxygenation, an oxygen management tool that aims to improve wine quality (Nguyen et al., 2010).

\subsection{Reductive sulfur compound in some New Zealand red and white wines}

The HS-SPME coupled with GC-MS method was employed to analyse some New Zealand commercial wines, including five white wines and five red wines, produced from different vintages from 2004 to 2008. Some older wines were included to look for the presence of as many reductive sulfur compounds as possible using the method developed, as high concentrations of some of these compounds are expected in older wines. The results obtained are displayed in Table 6. As can be seen from this table, ten out of the fourteen sulfur compounds that can be analysed using the HS-SPME coupled with GC-MS method, were quantified in these wines. Some compounds were present at fairly high levels, compared to their perception thresholds. The concentration of methanethiol (MeSH) was found to be higher than its perception threshold $(0.3 \mu \mathrm{g} / \mathrm{L}$ in alcoholic solution) in all of the analysed wines, while the concentrations of dimethyl sulfide were also relatively high 
compared to the reported threshold values, which range from $10-160 \mu \mathrm{g} / \mathrm{L}$. It was found that only small quantities of the other compounds, including disulfides, thioacetates and thioether alcohols, were present in the examined wines, with the exception of 3-methylthio1-propanol. The levels of these compounds were below their respective sensory thresholds, as can be seen from Table 6. DMTS was only found in the red wines examined, and at concentrations well above its perception threshold $(0.1 \mu \mathrm{g} / \mathrm{L})$. Interestingly, the concentrations of 3-methylthio-1-propanol were generally higher in the red wines than in the white wines, which followed the same trend reported by Fang \& Qian (2005). Informal sensory evaluation by a group of Wine Science Post Graduate students (University of Auckland, New Zealand) noticed that most of the white wines examined, except for one of the Chardonnay wines (Chd1), exhibited quite strong reductive characters, especially those with higher concentrations of DMS. On the other hand, reductive odours were only moderately noticeable in the Cabernet Sauvignon (CSav1) and the Merlot wines analysed. This was the case even though higher concentrations of the reductive sulfur compounds were found in the red wines, and the concentrations of some compounds, such as 3methylthio-1-propanol were higher than those of the white wines. This trend suggests that the complex red wine matrix could also play a role in the perception of the reductive notes. In a study on Spanish red wines, it was shown that the non-volatile components in the wines such as reducing sugars, alcohol and some phenolics, can have an impact on aroma sensory properties and thus on wine quality (Sáenz-Navajas et al., 2010).

\begin{tabular}{|c|c|c|c|c|c|c|c|c|c|c|}
\hline Compounds & MeSH & DMS & MTA & CS2 & DMDS & DMTS & ME & MTE & MTP & MTB \\
\hline $\begin{array}{l}\text { Threshold } \\
(\mu \mathrm{g} / \mathrm{L})\end{array}$ & 0.3 & $10-160$ & 300 & $>38$ & $20-45$ & 0.1 & 130 & 300 & 1200 & 100 \\
\hline 2008 SB1 & $\begin{array}{c}3.17 \pm \\
0.12\end{array}$ & $\begin{array}{c}19.1 \pm \\
0.9\end{array}$ & $\begin{array}{c}12.76 \pm \\
1.44\end{array}$ & $\begin{array}{c}1.62 \pm \\
0.06\end{array}$ & $\begin{array}{c}1.19 \pm \\
0.35\end{array}$ & nd & nd & $\begin{array}{c}23.2 \pm \\
0.7\end{array}$ & $\begin{array}{c}282 \pm \\
36\end{array}$ & nd \\
\hline 2005 SB2 & $\begin{array}{c}4.40 \pm \\
0.30\end{array}$ & $\begin{array}{c}32.3 \pm \\
0.6\end{array}$ & $\begin{array}{c}12.34 \pm \\
0.82\end{array}$ & $\begin{array}{c}0.59 \pm \\
0.07\end{array}$ & $\begin{array}{c}1.06 \pm \\
0.15\end{array}$ & nd & nd & nd & $\begin{array}{c}237 \pm \\
11\end{array}$ & nd \\
\hline 2008 Chd1 & nd & $9.1 \pm 0.2$ & nd & $\begin{array}{c}0.94 \pm \\
0.06 \\
\end{array}$ & nd & nd & nd & $\begin{array}{c}26.0 \pm \\
2.6 \\
\end{array}$ & $\begin{array}{c}624 \pm \\
50 \\
\end{array}$ & nd \\
\hline 2003 Chd2 & $\begin{array}{c}2.20 \pm \\
1.09\end{array}$ & $\begin{array}{c}14.77 \pm \\
0.01\end{array}$ & $\begin{array}{c}5.42 \pm \\
0.08\end{array}$ & $\begin{array}{c}1.61 \pm \\
0.01\end{array}$ & nd & nd & nd & $\begin{array}{c}18.5 \pm \\
1.4\end{array}$ & $230 \pm 9$ & nd \\
\hline 2006 Rslg & $\begin{array}{c}3.24 \pm \\
0.02\end{array}$ & $\begin{array}{c}39.3 \pm \\
0.7\end{array}$ & $\begin{array}{c}4.94 \pm \\
1.06\end{array}$ & $\begin{array}{c}0.71 \pm \\
0.01\end{array}$ & $\begin{array}{c}2.17 \pm \\
0.14\end{array}$ & nd & nd & nd & $\begin{array}{c}374 \pm \\
33\end{array}$ & nd \\
\hline 2006 PN1 & $\begin{array}{c}2.23 \pm \\
0.19\end{array}$ & $\begin{array}{c}36.3 \pm \\
0.5\end{array}$ & $\begin{array}{c}5.29 \pm \\
0.29\end{array}$ & $\begin{array}{c}1.48 \pm \\
0.09\end{array}$ & nd & nd & nd & $\begin{array}{c}26.7 \pm \\
1.0\end{array}$ & $\begin{array}{c}1064 \pm \\
61\end{array}$ & $\begin{array}{c}15.2 \pm \\
4.0\end{array}$ \\
\hline 2006 PN2 & $\begin{array}{c}4.13 \pm \\
0.14\end{array}$ & $\begin{array}{c}10.2 \pm \\
0.05\end{array}$ & $\begin{array}{c}8.16 \pm \\
2.56\end{array}$ & $\begin{array}{c}3.44 \pm \\
0.14\end{array}$ & $\begin{array}{c}5.71 \pm \\
0.61\end{array}$ & $\begin{array}{c}0.92 \pm \\
0.06\end{array}$ & nd & $\begin{array}{c}37.0 \pm \\
3.2\end{array}$ & $\begin{array}{c}625 \pm \\
54\end{array}$ & nd \\
\hline 2006 CSav1 & $\begin{array}{c}1.42 \pm \\
0.01\end{array}$ & $\begin{array}{c}54.4 \pm \\
1.6\end{array}$ & $\begin{array}{c}5.54 \pm \\
0.61\end{array}$ & $\begin{array}{c}7.18 \pm \\
0.30\end{array}$ & nd & $\begin{array}{c}0.87 \pm \\
0.01\end{array}$ & $\begin{array}{l}65.0 \pm \\
9.5\end{array}$ & $\begin{array}{c}27.8 \pm \\
1.2\end{array}$ & $\begin{array}{c}1119 \pm \\
27\end{array}$ & $\begin{array}{c}19.4 \pm \\
4.0\end{array}$ \\
\hline 2004 CSav2 & $\begin{array}{c}1.76 \pm \\
0.15\end{array}$ & $\begin{array}{c}11.5 \pm \\
1.2\end{array}$ & $\begin{array}{c}9.53 \pm \\
0.36\end{array}$ & $\begin{array}{c}2.67 \pm \\
0.03\end{array}$ & $\begin{array}{c}2.35 \pm \\
0.30\end{array}$ & $\begin{array}{c}0.90 \pm \\
0.04\end{array}$ & $\begin{array}{c}88.4 \pm \\
5.2\end{array}$ & $\begin{array}{c}32.4 \pm \\
3.4\end{array}$ & $\begin{array}{c}2350 \pm \\
133\end{array}$ & nd \\
\hline 2004 Mer & $\begin{array}{c}4.85 \pm \\
0.16\end{array}$ & $\begin{array}{c}27.0 \pm \\
0.4\end{array}$ & $\begin{array}{c}5.97 \pm \\
0.51\end{array}$ & $\begin{array}{c}1.32 \pm \\
0.03\end{array}$ & $\begin{array}{c}2.28 \pm \\
0.55\end{array}$ & $\begin{array}{c}0.88 \pm \\
0.03\end{array}$ & $\begin{array}{c}43.6 \pm \\
1.0\end{array}$ & $\begin{array}{c}38.3 \pm \\
2.5\end{array}$ & $\begin{array}{c}1213 \pm \\
8\end{array}$ & nd \\
\hline
\end{tabular}

Table 6. Concentrations of reductive sulfur compounds $(\mu \mathrm{g} / \mathrm{L}) \pm$ standard deviations of the means $(n=3)$ in ten commercial New Zealand white and red wines (SB = Sauvignon blanc, Chd $=$ Chardonnay, Rslg = Riesling, PN = Pinot noir, Csav = Cabernet Sauvignon, Mer $=$ Merlot). 


\subsection{Changes in the concentrations of reductive sulfur compounds in a red wine undergoing micro-oxygenation}

The GC-MS method was then employed in a study on the effects of micro-oxygenation ${ }^{8}$ (MOX) on the concentrations of reductive sulfur compounds in a red wine, commercially made from Vitis vinifera var. Cabernet Sauvignon grapes grown at Esk Valley, Hawkes Bay, New Zealand.

The grapes were harvested at $22.0^{\circ}$ Brix on the 13th April, 2008, crushed, destemmed and inoculated with Bio Springer BCS103 yeast (Bio Springer, Maisons-Alfort, France) at Corbans Winery (Hawkes Bay, New Zealand). The must was left to ferment on skins for 17 days before being drained off, centrifuged and pasteurised. The wine was then pumped onto a combination of French oak staves and untoasted oak chips at a rate of $2 \mathrm{~g} / \mathrm{L}$. The wine was then kept at $12{ }^{\circ} \mathrm{C}$ for 2 days to stabilise before oxygen was delivered in a fully replicated MOX trial, conducted using twelve $300 \mathrm{~L}$ tanks. Malolactic fermentation (MLF) occurred spontaneously at day 42 after MOX had been applied and was only completed towards the end of the trial. Oxygen dosing was carried out using a PARSEC SAEn 4000 Micro-oxygenation Unit supplied by Kauri New Zealand Ltd. (Wellington, New Zealand). Nine $300 \mathrm{~L}$ stainless steel tanks were used for the control (no oxygen supplied), the low oxygen $(5 \mathrm{mg} / \mathrm{L} / \mathrm{month})$ and high oxygen $(20 \mathrm{mg} / \mathrm{L} / \mathrm{month})$ rate treatments, while the other 3 tanks used for the third treatment were made of high density polyethylene, supplied by Flextank International (Abbotsford, Australia).

Seven reductive sulfur compounds, out of fourteen that could be analysed using the GC-MS procedure, were found in the Cabernet Sauvignon wine, and their concentrations were monitored at the beginning and the end of the trial. The highly volatile sulfur compounds (boiling point less than $90^{\circ} \mathrm{C}$ ) found to be present were methanethiol (MeSH) and dimethyl sulfide (DMS). The wine also contained five low volatile compounds (boiling point above 90 $\left.{ }^{\circ} \mathrm{C}\right)$, including dimethyl disulfide (DMDS), methyl thioacetate (MTA), S-ethyl thioacetate (ETA), 2-(methylthio)-1-ethanol (MTE) and 3-(methylthio)-1-propanol (MTP) (methionol).

\subsubsection{Methanethiol, dimethyl sulfide and dimethyl disulfide}

Methanethiol (MeSH) is one of the simplest sulfur compounds and plays a decisive role in reduction defects related to wine aromas (Ribéreau-Gayon et al., 2006b). The perception threshold of methanethiol in a hydroalcoholic solution is just $0.3 \mu \mathrm{g} / \mathrm{L}(\mathrm{ppb})$ and the compound can generate an odour reminiscent of cooked cabbage (Mestres et al., 2000).

In the current study, the concentration of $\mathrm{MeSH}$ in all of the wines was low and the wines were not overly reductive, as evaluated by local winemakers, although the concentrations were well above the perception threshold for MeSH. Our results indicated that at the end of the trial period, MOX did show some impact on the concentration of $\mathrm{MeSH}$ in the wine that received a higher oxygen dosage $(20 \mathrm{mg} / \mathrm{L} / \mathrm{month})$ and in the wine stored in Flextanks. In

\footnotetext{
${ }^{8}$ MOX is a technique that was developed in the Madiran region of southern France in the 1980s and was commercially released in 1996 (Cano-López et al., 2006). Its principle is the continuous delivery of a small metered amount of oxygen into a wine by means of micro-bubbling using a porous microdiffuser.
} 
these two cases, the concentration of $\mathrm{MeSH}$ was significantly lower than in the control wine and in the wine treated with the lower oxygen rate $(5 \mathrm{mg} / \mathrm{L} / \mathrm{month})$ (Fig.4).
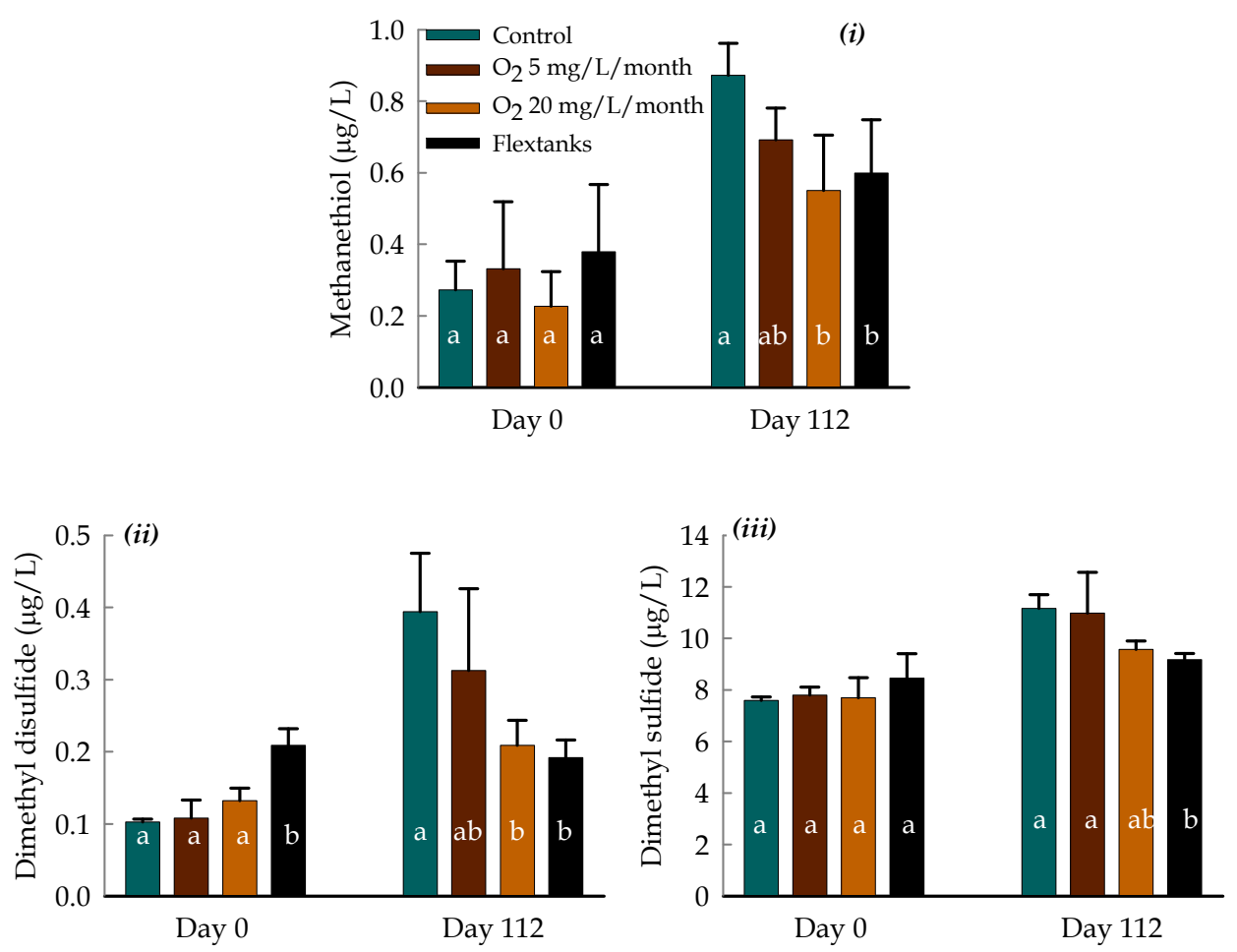

Fig. 4. Effect of MOX applied after alcoholic fermentation on (i) methanethiol, (ii) dimethyl disulfide and (iii) dimethyl sulfide in a Cabernet Sauvignon wine. Error bars represent the standard deviations of the mean $(n=3)$. Columns with different letters denote values which significantly differ ( $\mathrm{P}<0.05$, LSD and Tukey Post Hoc Tests) at the same observation date.

Our findings are in agreement with the study by McCord (2003) who reported a significant decrease in the concentration of $\mathrm{MeSH}$ and $\mathrm{EtSH}$ in a wine that underwent MOX. No biological activity was recorded in the wine used in the McCord study. However, spontaneous MLF did occur in the control and all treated wines during this MOX trial. Although the formation of methionine-derived reductive sulfur compounds from the metabolism of the lactic acid bacteria (LAB) Oenococcus oeni during MLF is still poorly understood, it was shown in a recent study that MLF may result in the formation of MeSH and DMDS (Vallet et al., 2008). In addition, thiols such as MeSH are nucleophilic compounds very susceptible to oxidation, and can readily react with different electrophilic species such as $o$-quinones and the carbocation form of procyanidin molecules, formed from the oxidation of wine polyphenols (Majcenovic et al., 2002; Ribéreau-Gayon et al., 2006b). 
MeSH can also be oxidised to form DMDS and dimethyl trisulfide (DMTS) (Rauhut, 1993). The concentration of DMDS, which has a perception threshold of $20-45 \mu \mathrm{g} / \mathrm{L}$ in wine with cooked-cabbage and onion like odours (Mestres et al., 2000), however, was significantly lower $(\mathrm{P}<0.05)$ in the wine treated with $20 \mathrm{mg} \mathrm{O} / \mathrm{L} / \mathrm{month}$ and in the Flextank wines (Fig.4), and DMTS was not detected in any of wines.

MOX did not affect the concentration of DMS, but the Flextank wine had a lower DMS concentration than the control (Fig.4). In McCord's study (2003), on the effect of toasted oak products with and without MOX on the ageing of a Cabernet Sauvignon wine, the concentration of DMS was found to decrease in all treatments with added toasted oak, while no such decrease was found in the micro-oxygenated counterparts. DMS can produce offodours described as cooked cabbage and shrimp-like at concentrations above its perception threshold (10 - $160 \mu \mathrm{g} / \mathrm{L}$ in wine), whereas at low levels it produces odours reminiscent of asparagus, corn and molasses (Mestres et al., 2000; Jackson, 2008). On the contrary, DMS is thought to have a positive influence on the bouquet of some bottled wines when present at low levels (Spedding \& Raut, 1982). The formation of DMS in wine has not yet been fully elucidated. Some researchers consider that cysteine, cystine and glutathione can be precursors of DMS, because yeasts cannot produce S-methyl methionine (SMM) (Landaud et al., 2008). On the other hand, it has been suggested that yeast may produce SMM, which subsequently can be enzymatically hydrolysed to release DMS and homoserine (Rauhut, 1993). The metabolism of LAB, e.g. Oenococcus oeni, during MLF, also produces diverse sulfur containing volatiles through methionine catabolism (Pripis-Nicolau et al., 2004). Although trace amounts of DMS were found in the basal medium inoculated with LAB strains, its formation did not correlate with methionine metabolism (Pripis-Nicolau et al., 2004). During wine ageing, the concentration of DMS can increase significantly, indicating that a chemical pathway could also be involved in its production (Landaud et al., 2008). Reduction of dimethyl sulfoxide (DMSO) (odourless), present at a concentration up to 1230 $\mu \mathrm{g} / \mathrm{L}$ in a survey of New Zealand wines, has been proposed as a DMS precursor during wine aging (de Mora et al., 1993).

On a further note, it was found in a model wine ageing study that DMSO is only a minor precursor of DMS, yet SMM appeared to be a good source of DMS during wine ageing (Segurel et al., 2005). Loscos et al. (2008), for the first time, isolated SMM from grapes and established that it is a major DMS precursor in the grape. In the current MOX study, MLF started spontaneously after day 42, so either chemical or biochemical pathways could be sources of DMS. This could explain the increase in concentration values at day 112 compared to day 0 in all of the wines. This increase, however, was lower in the high oxygen treated wine and significantly lower in the Flextank wine, suggesting a limited effect of oxygen on the enzymatic biosynthesis of DMS from the precursor SMM during the course of the trial. In this case, the LAB that predominated in the research wine during spontaneous MLF might have been a facultative anaerobic species, such as Oenococcus oeni and Lactobacillus, which are better adapted to the absence of oxygen (Ribéreau-Gayon et al., 2006a), and thus enhanced the enzymatic hydrolysis of SMM in the control and the low oxygen treated wine.

\subsubsection{S-thioesters}

The S-methyl and S-ethyl esters of ethanethioic acid, methyl and ethyl thioacetates (MTA and ETA) were also found and monitored during the MOX trial. These compounds were identified and determined for the first time in beer and wine by Leppanen et al. (1980). 
Despite their high sensory thresholds, the thioacetates are a potential source of off-odours, because they can be hydrolysed to give free thiols at low pH (Leppanen et al., 1980), although they can produce rotten vegetable smells on their own (Landaud et al., 2008). The formation of these esters could be due to wine yeast metabolism involving the highly volatile MeSH via acetyl coenzyme A (acetyl-CoA) (Landaud et al., 2008). In the present study, alcoholic fermentation had finished before oxygen was applied, so hydrolysis should have led to declines in the concentrations of MTA and ETA. In fact, the concentrations of both MTA and ETA in all wines did not show any difference among the treatments and with the control (Fig.5). This indicates that oxygen did not influence the hydrolysis process during the trial period, even though the ETA concentrations were different in the wines to start with. At the same time spontaneous MLF may have contributed to an increase in ETA concentrations in the control and the low oxygen treated wines, leading to similar levels of this compound in all of the wines at the end of the trial. During MLF, the metabolism of LAB can also transform sugars, organic acids or amino acids into aromatic compounds, including $\mathrm{MeSH}$. The availability of $\mathrm{MeSH}$, therefore, could lead to the formation of MTA through an enzymatic reaction between $\mathrm{MeSH}$ and acetyl-CoA. This mechanism has also been found to occur with yeast metabolism in beer (Landaud et al., 2008). However, whether such an enzyme catalysed reaction occurs in the metabolism of wine LAB has not yet been established.
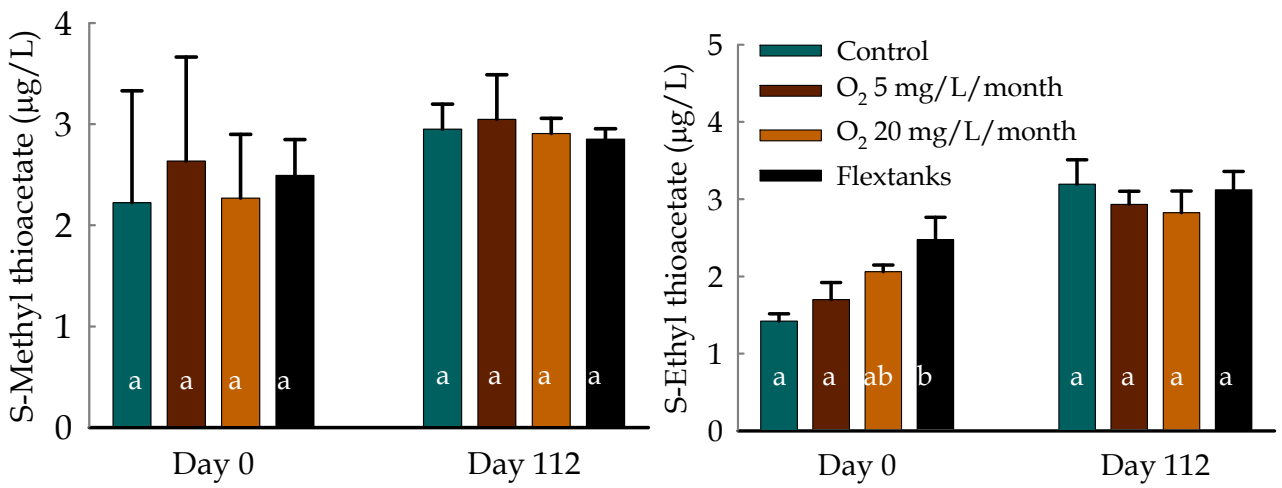

Fig. 5. Effect of MOX applied after AF on the S-thioesters in a Cabernet Sauvignon wine. Error bars represent the standard deviations of the mean $(n=3)$. Columns with different letters denote values which significantly differ ( $P<0.05$, LSD and Tukey Post Hoc Tests) at the same observation date.

\subsubsection{Thioether alcohols}

Two other low volatile sulfur compounds included in this study were 2-methylthio-1ethanol (MTE) and 3-methylthio-1-propanol or methionol (MTP). MTP is considered to be the most important heavy sulfur compound involved with reduction defects brought about by yeast activity (Ribéreau-Gayon et al., 2006b). MTP can generate odours reminiscent of cauliflower and cabbage at a concentration above its perception threshold $(1200 \mu \mathrm{g} / \mathrm{L})$. MTE 
has a perception threshold of $250 \mu \mathrm{g} / \mathrm{L}$ in hydroalcoholic solution and has a French beanlike odour (Mestres et al., 2000). The concentration of MTP in wines with reduction notes, due to the heavy sulfur compounds that develop during alcoholic fermentation, is typically found at levels above its perception threshold. The concentration of MTE in wines with reductive characters may be very close to its perception threshold (Ribéreau-Gayon et al., 2006b).
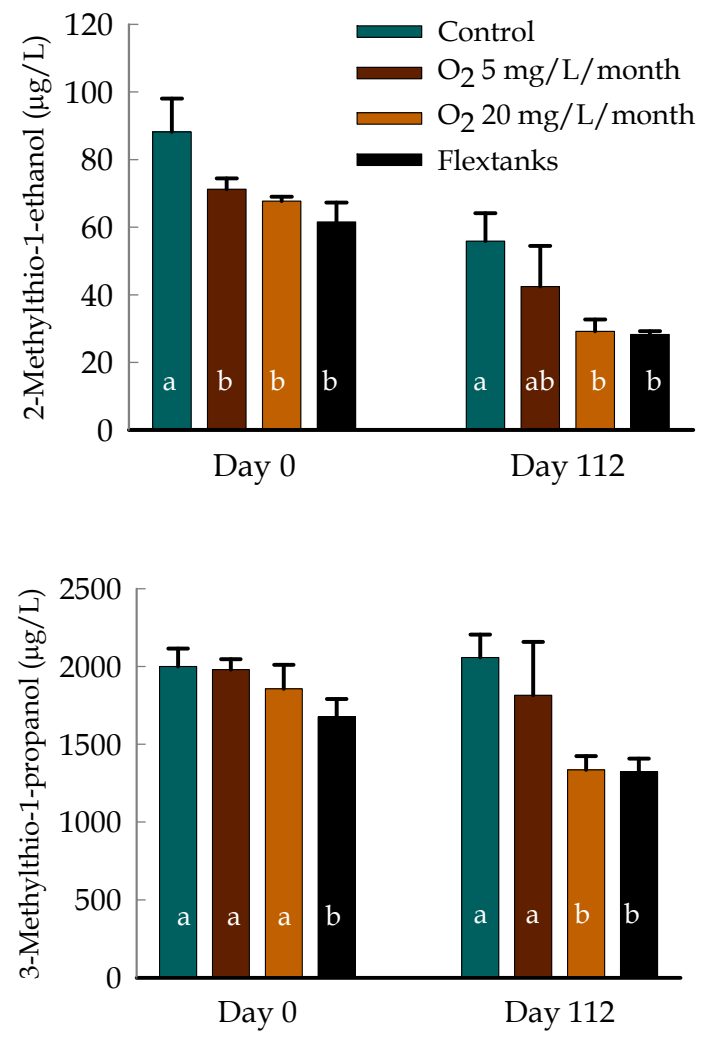

Fig. 6. Effect of MOX applied after AF on 2-methylthio-1-ethanol and 3-methylthio-1propanol. Error bars represent the standard deviations of the mean $(n=3)$. Columns with different letters denote values which significantly differ $(\mathrm{P}<0.05$, LSD and Tukey Post Hoc Tests) at the same observation date.

As can be seen from Fig.6, the concentration of MTE tended to decrease over time, with a greater drop in the high oxygen treated and Flextank wines at the end of the trial. However, possibly because of some variations caused during pumping the wine from the bulk storage tanks to the $300 \mathrm{~L}$ tanks, the MTE concentrations were different at day 0; so the question whether oxygen could have affected this compound during the trial is therefore undecided. Literature on the formation and evolution of MTE during winemaking is not well 
documented. On the other hand, the metabolic formation of MTP in wine, involving the deamination of methionine produced by yeast, decarboxylation, then reduction of methional to methionol (MTP) via the Ehrlich pathway, is well known. Because the alcoholic fermentation had finished, no additional MTP formation was expected during the course of the trial. Instead, the higher oxygen treated wine and the Flextank wine showed a significant drop in the concentration of MTP by the end of the trial. The loss of MTP could be due to direct oxidation of MTP to form methional. Some authors have demonstrated a decrease of methionol in the presence of oxygen along with methional formation (Escudero et al., 2000). However, methional may also be formed from methionine via the Strecker mechanism in the presence of a dicarbonyl compound (e.g. methylglyoxal). This pathway was shown to be the main source of methional in white wines treated with oxygen (Silva Ferreira et al., 2002). Silva Ferreira et al. (2003) in a further study did not find that methional was present in a Port wine treated with oxygen, and suggested that the decrease in MTP would lead to the formation of other compounds as yet unidentified.

\section{Conclusion}

The method developed allows the concurrent quantification of fourteen high and low volatile reductive sulfur compounds commonly found in wines. Importantly, both methanethiol and ethanethiol were analysed without the use of a cryotrap, with good recovery and repeatability. The concentrations of reductive sulfur compounds in finished white and red wines revealed that although more reductive sulfur compounds were found in the examined red wines, the reductive odours were only moderately percieved. By contrast, strong reductive characters were exhibited in most of the white wines, suggesting that the complex red wine matrix could play a role in the perception of the reductive notes. The findings from the micro-oxygenation (MOX) trial also provide quantitative data to address the lack of scientific information regarding one of the proposed beneficial effects of MOX, namely to diminish the concentration of unwanted reductive sulfur compounds in red wines. MOX was applied to a Cabernet Sauvignon wine after the alcoholic fermentation in this study, and the results showed that oxygen could lower the concentration of MeSH. This may occur through an interaction with oxidised polyphenol quinones, but without an associated increase in the concentration of the disulfide DMDS, expected through direct oxidation of MeSH. More research is needed in this area to confirm the reaction pathways for the oxidation of methanethiol, and the potential formation of polyphenol adducts. The concentrations of other reductive sulfur compounds, except the thioesters, were also affected by the presence of oxygen. These losses have the potential to impact in a favorable manner on the removal of unwanted reductive odours from red wines. This issue also needs to be examined in future studies combining sensory analysis with the chemical analysis of reductive sulfur compounds.

\section{Acknowledgement}

The authors would like to thank Pernod Ricard New Zealand for the winemaking, Kauri Wine Product New Zealand Ltd. (Wellington, New Zealand) for generously providing the PARSEC micro-oxygenation units, and Flextank International for the supply of $300 \mathrm{~L}$ 
vessels. The authors would also like to recognise Teresa Murphy and Stuart I. Dykes at Corbans winery - Pernod Ricard New Zealand for logistical arrangements and sample collection of the micro-oxygenated wines.

\section{References}

Cano-López, M., Pardo-Minguez, F., López-Roca, J. M., \& Gómez-Plaza, E. (2006). Effect of microoxygenation on anthocyanin and derived pigment content and chromatic characteristics of red wines. American Journal of Enology and Viticulture, 57(3), 325331.

De Mora, S. J., Lee, P., Shooter, D., \& Eschenbruch, R. (1993). The analysis and importance of dimethylsulfoxide in wine. American Journal of Enology and Viticulture, 44(3), 327332.

Escudero, A., Hernandez-Orte, P., Cacho, J., \& Ferreira, V. (2000). Clues about the role of methional as character impact odorant of some oxidized wines. Journal of Agricultural and Food Chemistry, 48(9), 4268-4272.

Fang, Y., \& Qian, M. C. (2005). Sensitive quantification of sulfur compounds in wine by headspace solid-phase microextraction technique. Journal of Chromatography A, 1080(2), 177-185.

Fedrizzi, B., Magno, F., Moser, S., Nicolini, G., \& Versini, G. (2007). Concurrent quantification of light and heavy sulphur volatiles in wine by headspace solidphase microextraction coupled with gas chromatography/mass spectrometry. Rapid Communications in Mass Spectrometry, 21(5), 707-714.

Jackson, R. S. (2008). Wine science: principles, practice, perception (3nd ed.). San Diego: Academic Press.

Landaud, S., Helinck, S., \& Bonnarme, P. (2008). Formation of volatile sulfur compounds and metabolism of methionine and other sulfur compounds in fermented food. Applied Microbiology \& Biotechnology, 77(6), 1191-1205.

Lee, P. W., \& Aizawa, H. (Eds.). (2003). Handbook of residue analytical methods for agrochemicals Chichester, West Sussex, England ; Hoboken, NJ: Wiley.

Leppanen, O. A., Denslow, J., \& Ronkainen, P. P. (1980). Determination of thiolacetates and some other volatile sulfur compounds in alcoholic beverages. Journal of Agricultural and Food Chemistry, 28(2), 359-362.

Loscos, N., Ségurel, M., Dagan, L., Sommerer, N., Marlin, T., \& Baumes, R. (2008). Identification of S-methylmethionine in Petit Manseng grapes as dimethyl sulphide precursor in wine. Analytica Chimica Acta, 621(1), 24-29.

Majcenovic, A. B., Schneider, R., Lepoutre, J. P., Lempereur, V., \& Baumes, R. (2002). Synthesis and stable isotope dilution assay of ethanethiol and diethyl disulfide in wine using solid phase microextraction. Effect of aging on their levels in wine. Journal of Agricultural and Food Chemistry, 50(23), 6653-6658.

McCord, J. (2003). Application of toasted oak and micro-oxygenation to ageing of Cabernet Sauvignon wines. Australian \& New Zealand Grapegrower and Winemaker, 474, 43-53.

Mestres, M., Busto, O., \& Guasch, J. (2000). Analysis of organic sulphur compounds in wine aroma. Journal of Chromatography A, 881, 569-581. 
Mestres, M., Busto, O., \& Guasch, J. (2002). Application of headspace solid-phase microextraction to the determination of sulphur compounds with low volatility in wines. Journal of Chromatography A, 945(1-2), 211-219.

Nguyen, D.-D., Nicolau, L., Dykes, S. I., \& Kilmartin, P. A. (2010). Influence of microoxygenation on reductive sulfur off-odors and color development in a Cabernet Sauvignon wine. American Journal of Enology Viticulture, 61(4), 457464.

Otles, S. (Ed.). (2009). Handbook of food analysis instruments. New York, USA: CRC Press.

Pawliszyn, J. (1997). Solid phase microextraction: Theory and practice. New York: Wiley$\mathrm{VCH}$.

Pripis-Nicolau, L., Revel, G. D., Bertrand, A., \& Lonvaud-Funel, A. (2004). Methionine catabolism and production of volatile sulphur compounds by Oenococcus oeni. Journal of Applied Microbiology, 96(5), 1176-1184.

Rauhut, D. (1993). Production of sulfur compounds. In G. H. Fleet (Ed.), Wine microbiology and biotechnology (pp. 183-242). Chur, Switzerland: Harwood Academic Publishers.

Ribéreau-Gayon, P., Dubourdieu, D., Doneche, B., \& Lonvaud, A. (2006a). Handbook of enology - The microbiology of wine and vinifications (2nd ed. Vol. 1). Chichester, England ; Hoboken, NJ: John Wiley.

Ribéreau-Gayon, P., Glories, Y., Maujean, A., \& Dubourdieu, D. (2006b). Handbook of enology - The chemistry of wine stabilization and treatments (2nd ed. Vol. 2). Chichester, England ; Hoboken, NJ: John Wiley.

Sáenz-Navajas, M. A.-P., Tao, Y.-S., Dizy, M., Ferreira, V., \& Fernández-Zurbano, P. N. (2010). Relationship between nonvolatile composition and sensory properties of premium Spanish red wines and their correlation to quality perception. [doi: 10.1021/jf102546f]. Journal of Agricultural and Food Chemistry, 58(23), 1240712416.

Segurel, M. A., Razungles, A. J., Riou, C., Trigueiro, M. G. L., \& Baumes, R. L. (2005). Ability of possible DMS precursors to release DMS during wine aging and in the conditions of heat-alkaline treatment. Journal of Agricultural and Food Chemistry, 53(7), 2637-2645.

Silva Ferreira, A. C., Guedes De Pinho, P., Rodrigues, P., \& Hogg, T. (2002). Kinetics of oxidative degradation of white wines and how they are affected by selected technological parameters. Journal of Agricultural and Food Chemistry, 50(21), 59195924.

Silva Ferreira, A. C., Rodrigues, P., Hogg, T., \& Guedes De Pinho, P. (2003). Influence of some technological parameters on the formation of dimethyl sulfide, 2mercaptoethanol, methionol, and dimethyl sulfone in Port wines. Journal of Agricultural and Food Chemistry, 51(3), 727-732.

Spedding, D. J., \& Raut, P. (1982). The influence of dimethyl sulphide and carbon disulfide in the bouquet of wines. Vitis, 21, 240-246. 
Vallet, A., Lucas, P., Lonvaud-Funel, A., \& De Revel, G. (2008). Pathways that produce volatile sulphur compounds from methionine in Oenococcus oeni. Journal of Applied Microbiology, 104(6), 1833-1840. 


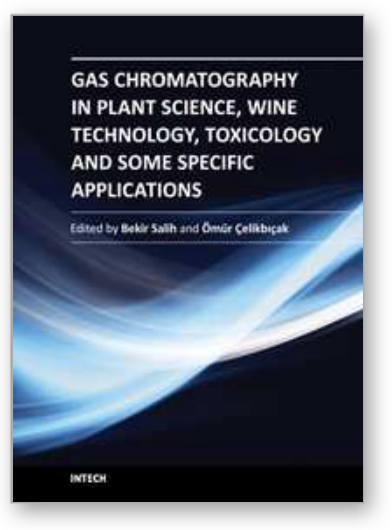

\author{
Gas Chromatography in Plant Science, Wine Technology, \\ Toxicology and Some Specific Applications \\ Edited by Dr. Bekir Salih
}

ISBN 978-953-51-0127-7

Hard cover, 346 pages

Publisher InTech

Published online 29, February, 2012

Published in print edition February, 2012

The aim of this book is to describe the fundamental aspects and details of certain gas chromatography applications in Plant Science, Wine technology, Toxicology and the other specific disciplines that are currently being researched. The very best gas chromatography experts have been chosen as authors in each area. The individual chapter has been written to be self-contained so that readers may peruse particular topics but can pursue the other chapters in the each section to gain more insight about different gas chromatography applications in the same research field. This book will surely be useful to gas chromatography users who are desirous of perfecting themselves in one of the important branch of analytical chemistry.

\title{
How to reference
}

In order to correctly reference this scholarly work, feel free to copy and paste the following:

Dang-Dung Nguyen, Laura Nicolau and Paul A. Kilmartin (2012). Application of an Automated Headspace Solid Phase Micro-Extraction for the GC-MS Detection and Quantification of Reductive Sulfur Compounds in Wines, Gas Chromatography in Plant Science, Wine Technology, Toxicology and Some Specific Applications, Dr. Bekir Salih (Ed.), ISBN: 978-953-51-0127-7, InTech, Available from: http://www.intechopen.com/books/gaschromatography-in-plant-science-wine-technology-toxicology-and-some-specific-applications/application-ofan-automated-headspace-solid-phase-micro-extraction-for-the-gc-ms-detection-and-quant

\section{INTECH}

open science | open minds

\author{
InTech Europe \\ University Campus STeP Ri \\ Slavka Krautzeka 83/A \\ 51000 Rijeka, Croatia \\ Phone: +385 (51) 770447 \\ Fax: +385 (51) 686166 \\ www.intechopen.com
}

\author{
InTech China \\ Unit 405, Office Block, Hotel Equatorial Shanghai \\ No.65, Yan An Road (West), Shanghai, 200040, China \\ 中国上海市延安西路65号上海国际贵都大饭店办公楼405单元 \\ Phone: +86-21-62489820 \\ Fax: +86-21-62489821
}


(C) 2012 The Author(s). Licensee IntechOpen. This is an open access article distributed under the terms of the Creative Commons Attribution 3.0 License, which permits unrestricted use, distribution, and reproduction in any medium, provided the original work is properly cited. 